\title{
Low Wavelength Loss of Germanium Doped Silica Fibers
}

\author{
Pedersen, Anders Tegtmeier; Grüner-Nielsen, Lars; Rottwitt, Karsten
}

Published in:

Optical Fiber Communication Conference and Exposition

Link to article, DOI:

10.1109/OFC.2008.4528753

Publication date:

2008

Document Version

Publisher's PDF, also known as Version of record

Link back to DTU Orbit

Citation (APA):

Pedersen, A. T., Grüner-Nielsen, L., \& Rottwitt, K. (2008). Low Wavelength Loss of Germanium Doped Silica Fibers. In Optical Fiber Communication Conference and Exposition (pp. 1-3). Optical Society of America. https://doi.org/10.1109/OFC.2008.4528753

\section{General rights}

Copyright and moral rights for the publications made accessible in the public portal are retained by the authors and/or other copyright owners and it is a condition of accessing publications that users recognise and abide by the legal requirements associated with these rights.

- Users may download and print one copy of any publication from the public portal for the purpose of private study or research.

- You may not further distribute the material or use it for any profit-making activity or commercial gain

- You may freely distribute the URL identifying the publication in the public portal

If you believe that this document breaches copyright please contact us providing details, and we will remove access to the work immediately and investigate your claim. 


\title{
Low Wavelength Loss of Germanium Doped Silica Fibers
}

\author{
Anders Tegtmeier Pedersen ${ }^{\dagger}$, Lars Grüner-Nielsen ${ }^{\dagger \dagger}$, Karsten Rottwitt ${ }^{\dagger}$ \\ ${ }^{\dagger}$ COM•DTU Department of Communications, Optics and Materials, Technical University of \\ Denmark, DK-2800 Kgs. Lyngby, Denmark \\ ${ }^{\dagger \dagger}$ OFS Fitel Denmark ApS, Priorparken 680, DK-2605 Brøndby, Denmark \\ s011663@com.dtu.dk
}

\begin{abstract}
Attenuation of four step-index fibers are measured with high accuracy from $190 \mathrm{~nm}$ to $1700 \mathrm{~nm}$. The spectra are deconvolved into different contributions and the influence of the Urbach edge at transmission wavelengths is investigated.

(C) 2005 Optical Society of America

OCIS codes: (060.2270) Fiber characterization; (060.2400) Fiber properties
\end{abstract}

\section{Introduction}

The spectral attenuation of silica based optical fibers has been subject to research over several decades due to the use of optical fibers in high capacity optical communication systems and consequently the importance of having a low loss. However, most of the research has been focused on wavelengths at or near the communication wavelengths, i.e from $1500 \mathrm{~nm}$ to $1600 \mathrm{~nm}$. In this work we report on measurements of the attenuation in a wide spectral range (190 $\mathrm{nm}$ to $1700 \mathrm{~nm}$ ) in order to investigate how the attenuation at low wavelengths affects the attenuation at communication wavelengths.

In the ultraviolet wavelength range the attenuation is dominated by spectrally localized absorption centers due to defects in the glass network. These absorption centers have been investigated thoroughly and the list of reported centers is extensive [1,2]. Especially defects concerning germanium play an important role for absorption centers localized in the wavelength range from $200 \mathrm{~nm}$ to $400 \mathrm{~nm}$. Despite a significant effort, there seem to be no complete agreement regarding the exact location of the centers and especially not about the exact physical defects causing them.

An exponentially decaying spectral dependence of the attenuation known as the Urbach edge was first described in [3]. Throughout the years this dependence has proven to be valid in a wide range of materials including germanium doped silica glass. The Urbach loss can in this material be expressed as:

$$
\alpha(\lambda)=f\left(X_{\mathrm{Ge}_{2} \mathrm{O}}\right) \exp \left[\frac{\gamma}{\lambda}\right]
$$

where $f$ is a function of the germanium content in the glass and $\gamma$ is a constant, stating that the decay of the exponential is the same for all germanium doping levels. An expression of this kind was first presented in [4].

In this paper we present attenuation spectra from $190 \mathrm{~nm}$ to $1700 \mathrm{~nm}$ of four step-index silica fibers with different germanium content. The four fibers are:

1. a standard non shifted transmission fiber

2. a fiber of the same type as 1 , but manufactured in an oxygen deficient environment, hence the concentration of defects is expected to be higher

3. a low germanium concentration fiber

4. a pure silica-core fiber

In the following, the spectra are deconvolved into contributions from different absorption centers in addition to Rayleigh scattering and the Urbach and the infrared edge. Accurate measurements, even in the ultraviolet range allow us not only to fit the ultraviolet absorption, but also to evaluate the Urbach edge and its impact all the way up to communication wavelengths.

\section{Experimental Setup}

The attenuation of four different step-index fibers were measured using the Cutback Method. In each fiber, the transmission through a length of fiber is compared against the transmission of a reference measurement of the same fiber. For wavelengths above $700 \mathrm{~nm}$ we use a commercial Photon Kinetics 2500-setup for measuring the attenuation. For 


\section{OWO7.pdf}

measurements in the 500-700 nm range we use a halogen lamp and an ANDO AQ-6315A optical spectrum analyzer (OSA). Below $500 \mathrm{~nm}$ we use a deuterium lamp in combination with a Spectro 320 optical spectrum analyzer.

As the loss increases with decreasing wavelength the fiber under test must be cut to shorter and shorter lengths down to lengths shorter than one millimeter, eventually making it technically impossible to record a loss spectrum on a single piece of fiber. To work around this problem a length of pure silica-core fiber is fusion spliced to either end of the fiber under test, see Fig. 1. To ensure consistent measurements, the fiber under test can not be removed from neither the light source nor the OSA between the first measurement and the reference measurement. Therefore, a dummy splice is introduced in the first measurement making it possible to cut the fiber back. This technique has been used on fiber lengths down to a few centimeters. For measurements on even shorter pieces of fiber we employ the technique described in [5], where the fiber under test and the extension fibers are mechanically fixed in a V-groove in a glass plate. The measurements in the different wavelength ranges have been combined to give a full spectrum.

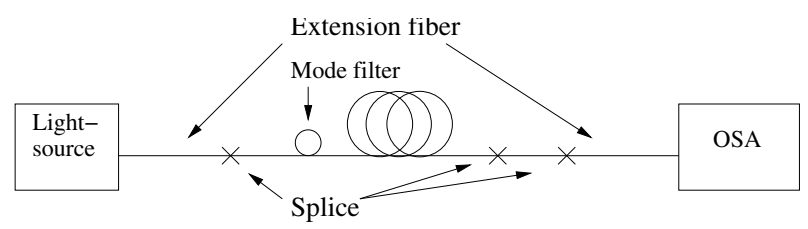

Fig. 1. Schematic drawing of the setup used to measure attenuation of fibers less than about $1 \mathrm{~m}$, which corresponds to a wavelength around 350 $\mathrm{nm}$. The extension fibers are pure silica-core fibers which has a lower attenuation in the visible and ultraviolet range compared to germanium doped fibers. The mode filter is used to filter out false peaks where a mode reaches cut off.

\section{Experimental Results}

Fig. 2. (a) shows attenuation spectra, from $190 \mathrm{~nm}$ to $1700 \mathrm{~nm}$, of all four fibers, all exhibiting a minima at $1570 \mathrm{~nm}$ and a water-peak at $1383 \mathrm{~nm}$, as expected. In the ultraviolet range the attenuation is dominated by spectrally very localized absorption centers that are different in the four fibers. These are illustrated in Fig. 2. (b), where the attenuation spectra from $190 \mathrm{~nm}$ to $450 \mathrm{~nm}$ are shown in detail for the four fibers. The fibers 1-3 all contain germanium and show the same characteristic peaks around $242 \mathrm{~nm}$ and $329 \mathrm{~nm}$. Both of these peaks are well described and are attributed to the same germanium oxygen-deficient center [1]. Furthermore, a shoulder on the $242 \mathrm{~nm}$ peak is visible around $280 \mathrm{~nm}$. We attribute this to a nonbridging oxygen hole center with a peak absorption located at $260 \mathrm{~nm}$ [1]. Fiber 4 does not contain germanium and the characteristic features mentioned above are not seen in this spectrum. Rather we see a peak at $247 \mathrm{~nm}$ which we attribute to a corresponding silicon oxygen-deficient center [2].

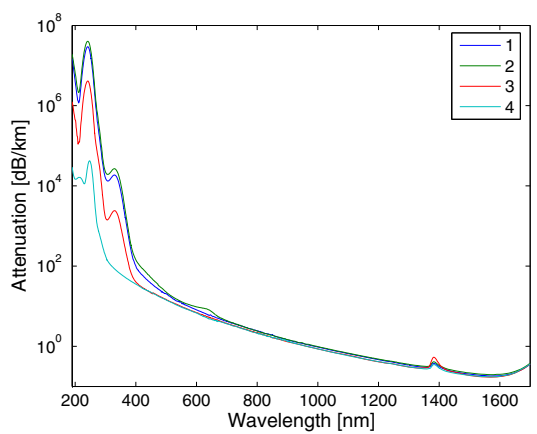

(a)

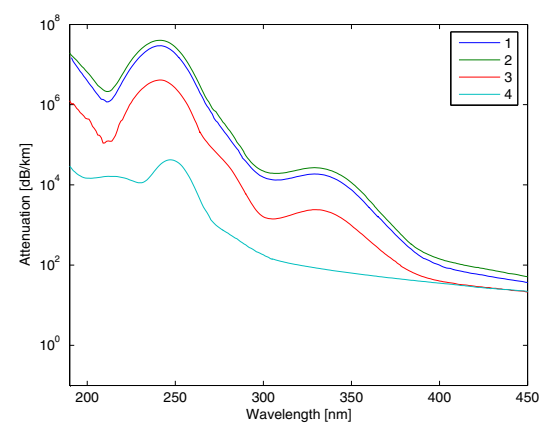

(b)

Fig. 2. (a) Comparison of the attenuation of the four fibers in the full measured wavelength range $190 \mathrm{~nm}$ to $1700 \mathrm{~nm}$. (b) Comparison of the attenuation of the four fibers in the wavelength range $190 \mathrm{~nm}$ to $450 \mathrm{~nm}$.

The measured data are used as basis for an iterative least squares fit of an appropriate function describing the attenuation. The following expression has been used:

$$
\begin{aligned}
\alpha_{\mathrm{fit}}(\lambda) & =A_{\text {Urbach }} \exp \left[\frac{\gamma}{\lambda}\right]+A_{\text {Rayleigh }} \lambda^{-4}+A_{\mathrm{IR}} \exp \left[\frac{-\delta}{\lambda}\right] \\
& +\sum_{i} A_{\text {Gauss }} \exp \left[-\left(\frac{\lambda-\lambda_{i}}{\sigma_{i}}\right)^{2}\right]+\sum_{j} \frac{A_{\text {Lorentz }}}{1+\left[\frac{1 / \lambda+1 / \lambda_{j}}{\sigma_{j}}\right]^{2}}
\end{aligned}
$$




\section{OW07.pdf}

where the terms on the right hand side represents - from left to right - the Urbach absorption, the Rayleigh absorption, the infrared absorption and finally the two sums represents contributions from absorption centers expressed as Gaussians and Lorentzians, respectively. $A$ is the strength of each contribution and $\sigma_{i, j}$ specifies the width of the Gaussians and Lorentzians, respectively. For simplicity, a Gaussian spectral dependence of the absorption centers have been used to model most of the absorption centers. Although the water peak at $1383 \mathrm{~nm}$ has been modelled using a sum of a Gaussian and four Lorentzians as described in [6]. The agreement between the theoretical fit to the absorption and the measured data is better than $10 \%$ for all four fibers in the full spectrum.

Table 1. The fitted Urbach-coefficients together with the measured total loss and the Urbach contribution at $1550 \mathrm{~nm}$ for the four spectra. The last column is the percentage of the overall loss at $1550 \mathrm{~nm}$ constituted by the Urbach edge.

\begin{tabular}{lccccc}
\hline Fiber & $\begin{array}{c}A_{\text {Urbach }} \\
{[\mathrm{dB} / \mathrm{km}]}\end{array}$ & $\begin{array}{c}\gamma \\
{[\mu \mathrm{m}]}\end{array}$ & $\begin{array}{c}\alpha_{\text {total }} \\
{[\mathrm{dB} / \mathrm{km}]}\end{array}$ & $\begin{array}{c}\alpha_{\text {Urbach }} \\
{[\mathrm{dB} / \mathrm{km}]}\end{array}$ & $\begin{array}{c}\text { Urbach share of } \alpha_{\text {total }} \\
{[\%]}\end{array}$ \\
\hline 1 standard & $3.46 \cdot 10^{-4}$ & 4.59 & 0.187 & $6.69 \cdot 10^{-3}$ & 3.58 \\
2 oxygen deficient & $7.77 \cdot 10^{-4}$ & 4.55 & 0.201 & $1.47 \cdot 10^{-2}$ & 7.31 \\
3 low germanium & $3.43 \cdot 10^{-5}$ & 4.54 & 0.173 & $6.41 \cdot 10^{-4}$ & 0.37 \\
4 pure silica & $1.33 \cdot 10^{-6}$ & 4.45 & 0.176 & $2.34 \cdot 10^{-5}$ & 0.01 \\
\hline
\end{tabular}

Table 1 shows the fitted parameters $A_{\text {Urbach }}$ and $\gamma$ presented in eqn. (1) as well as the Urbach contribution at $1550 \mathrm{~nm}$. We see that the decay rate, $\gamma$, of the Urbach contribution for all spectra are very close to each other even for fiber 4 which does not contain germanium. Furthermore the contribution of the Urbach edge at $1550 \mathrm{~nm}$ for fibers 1 and 2 is $3.58 \%$ respectively $7.31 \%$ which is significant. For fibers 3 and 4 the contribution is more modest. Fig. 3 shows the Urbach edge of all four fibers in the full spectral range.

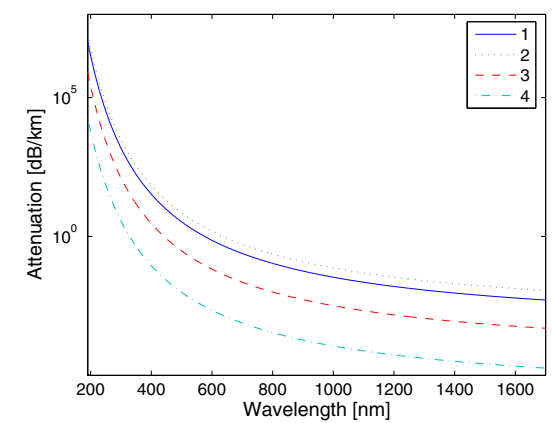

Fig. 3. The Urbach contribution to the attenuation vs wavelength for all four fibers. The decay rate of each graph is seen to be almost the same.

\section{Conclusion}

We have measured the attenuation spectra of four different step-index fibers from $190 \mathrm{~nm}$ to $1700 \mathrm{~nm}$ with high accuracy. The resulting spectra have been deconvolved into different loss contributions and used to investigate the validity of eqn. (1) and thereby also the effect of Urbach loss at communication wavelengths. We find that the decay of the exponential Urbach contribution is very consistent for all fibers, even for fiber 4 which does not contain Germanium. The Urbach contribution furthermore turns out to be considerable at communication wavelengths. Especially for the standard non shifted transmission fiber.

\section{References}

1. V. B. Neustruev, "Colour centres in germanosilicate glass and optical fibres", J. Phys.: Condens. Matter 6 6901-6936 (1994).

2. Linards Skuja, "Optically active oxygen-deficiency-related centers in amorphous silicon dioxide", Journal of NON-crystalline Solids 239 16-48 (1998).

3. Franz Urbach, "The Long-Wavelength Edge of Photographic Sensitivity and of the Electronic Absorption of Solids", Phys. Rev. 92 1324 (1953).

4. P.C. Schultz, Proc. 11th Int. Glass Congress 3 155-63 (1977).

5. Robert M. Atkins, "Measurements of the ultraviolet absorption spectrum of optical fibers", Optics Letters 17 469-471 (1992).

6. M. Bredol, D. Leers, L. Bosselaar and M. Hutjens, "Improved Model for OH Absorption in Optical Fibers", Journal of Lightwave Technology 8 1536-1540 (1990). 